\title{
Energy Cost Assessment of an Industrial Wastewater Treatment Plant: Effect of Design Flow
}

\author{
*Pelin Yapıcıoğlu \\ *Faculty of Engineering, Department of Environmental Engineering, Harran University, Turkey
}

\begin{abstract}
Wastewater treatment plants are widely used to decrease harmful discharges to receiving water bodies. These plants are regarded as the top energy consumers by municipalities. Energy demand of a plant depends on the volume of wastewater treated, organic load and effluent quality requirement etc. In order to ensure energy efficiency in these plants, it should be focused on these parameters. In this study, the impacts of design parameters on energy cost for a dairy wastewater treatment plant were investigated. This paper aims to reveal the role of design flow on energy efficiency. An indicator parameter that is energy cost indicator has been used. This indicator was calculated for both design wastewater flow and operational wastewater flow. The results show that energy cost indicator of operational flow was higher than design flow that were $2.1 \times 10^{-8}$ and $2.36 \times 10^{-27}$, respectively. If plants are operated in design flows, energy cost can be decreased.
\end{abstract}

Key words: Energy cost, energy efficiency, design parameters, wastewater treatment plant

\section{Introduction}

Wastewater treatment plants (WWTPs) are commonly used to prevent harmful discharges to receiving water bodies [1]. These plants are considered as one of the top energy consumers by the municipalities [2,3]. Energy consumption leads to the greenhouse gas emissions which are the component of global warming in WWTPs [4]. Electricity consumption in a WWTP causes to the indirect greenhouse gas emissions therefor electricity consumption should take under control for the reduction of greenhouse gas emissions [5, 6]. Also, there is an economic dimension of the electricity consumption.

Energy demand of a plant is based on the volume of treated wastewater (wastewater flow rate), organic loading rate and effluent quality requirement etc. [7]. In order to obtain energy efficiency and to decrease the energy costs in WWTPs, it should be focused on these operational parameters.

Operational parameters of the wastewater treatment plants do not match the design parameters for several reasons such as the inaccurate estimation of the population served or production capacity of the industries, in general [2]. This mismatch has an unfavorable impact on the performance of the WWTPs and their energy costs and consumption. The major parameter is the wastewater flow rate among operational parameters. Differences between the operational wastewater flow and the design flow are responsible for inefficiencies in the process, so pollutant removal decreases and *Corresponding author: Pelin Yapıcıŏlu Address: Faculty of Engineering, Department of Environmental Engineering, Harran University, Turkey, Şanlıurfa TURKEY. E-mail address: pyapicioglu@harran.edu.tr, Phone: $+904143181460$ 
operational costs in terms of energy, reagents and maintenance increases [8]. Especially, for the industrial WWTPs, the types of production (batch or continue), production capacity variations are the major factors that lead to the mismatches. In particular, the production capacity affects the operational wastewater flow in terms of the quantity of treated wastewater in industrial WWTPs.

The aim of this paper is to reveal the role of design flow on energy efficiency and cost. The effects of design flow rate for a dairy wastewater treatment plant on energy cost were investigated and benchmarked with the operational inflow.

\section{Materials and Method}

In this paper, the estimation of the energy cost of the dairy wastewater treatment plant was based on the model developed by Hernandez-Sancho et al. (2011a) [9]. In this model, the performance index (Z) and energy cost indicator (ECI) that is derived from " $Z$ " have been used. This indicator was calculated for both design wastewater flow and operational wastewater flow and then the results were benchmarked.

\subsection{Description of the dairy wastewater treatment plant}

The dairy industry is located in Turkey. In this study, a full-scale wastewater treatment plant of a dairy plant in Turkey was elected as the pilot plant, having 550 tons/day raw cow's milk processing capacity. The main products being processed are drinking milk, fruit juice, cream, milk powder, yoghurt and butter. The main wastewater generating points of the industry are the clarification, pasteurization and homogenization processes. The wastewater plant's characteristics used in this study were given in Table 1. The wastewater analysis results were ensured using Standard Methods [10]. This industrial plant is a type of small-scale plants. Figure 1 demonstrates the wastewater treatment process flow scheme.

Table 1. Data Set of Dairy WWTP

\begin{tabular}{cc}
\hline Parameter & Value \\
\hline Operational flow rate (Q) & $2100 \mathrm{~m}^{3} / \mathrm{d}$ \\
Design flow rate (q) & $3500 \mathrm{~m}^{3} / \mathrm{d}$ \\
Influent biological oxygen demand (BOD $)$ & $6.48 \mathrm{~g} / \mathrm{m}^{3}$ \\
\hline
\end{tabular}




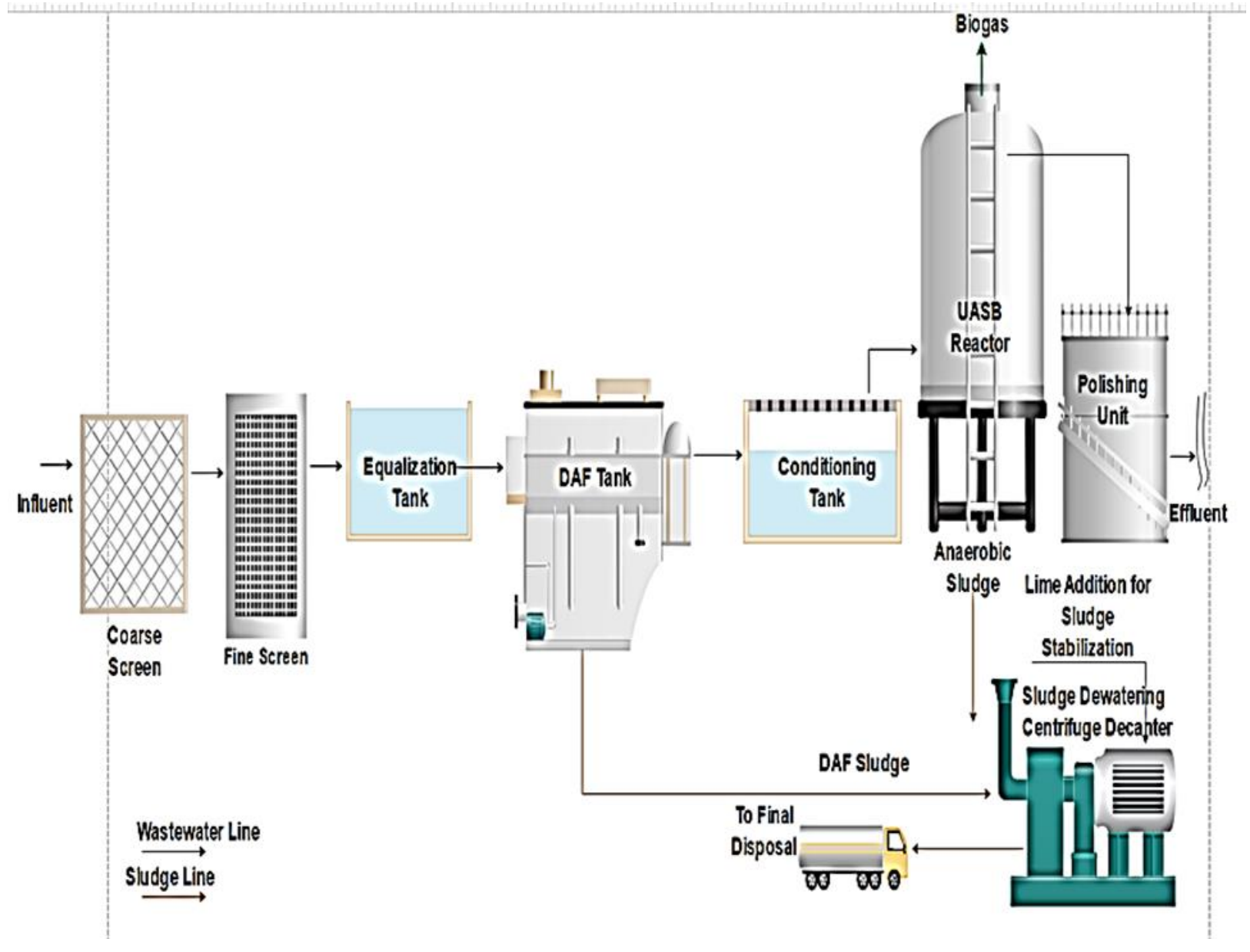

Figure 1. Wastewater treatment process flow scheme of dairy industry

\subsection{Performance index $(\mathrm{Z})$}

The performance index $(\mathrm{Z})$ consists of two components which are the operational flow rate $(\mathrm{Q})$ $\left(\mathrm{m}^{3} / \mathrm{d}\right)$ and the design flow of the plant (q) $\left(\mathrm{m}^{3} / \mathrm{d}\right)$. Eq. 1 shows the calculation of $\mathrm{Z}$ [2].

$Z=\frac{|\mathrm{q}-\mathrm{Q}|}{Q} \cdot 100$ 


\subsection{Energy cost indicator (ECI)}

Energy cost indicator (ECI) has been derived from Z, the volume of wastewater treated per year (V) $\left(\mathrm{m}^{3} / \mathrm{y}\right)$ and biological oxygen demand $\left(\mathrm{g} / \mathrm{m}^{3}\right)$. In this study, ECI values related to design flow (ECI design flow) and operational flow (ECI operational flow) were calculated and benchmarked. In Eq. 2 , the calculation model of ECI for small scale WWTPs was given [2,9].

$\mathrm{ECI}=1983.10^{6} \mathrm{~V}^{0.717} \mathrm{e}^{\left(-14.327 \mathrm{BOD}_{5}+0.660 \mathrm{Z}\right)}$

\section{Results}

The results revealed that energy cost indicator of operational flow was higher than design flow that were $2.1 \times 10^{-8}$ and $2.36 \times 10^{-27}$, respectively. Figure 2 shows the comparison of them.

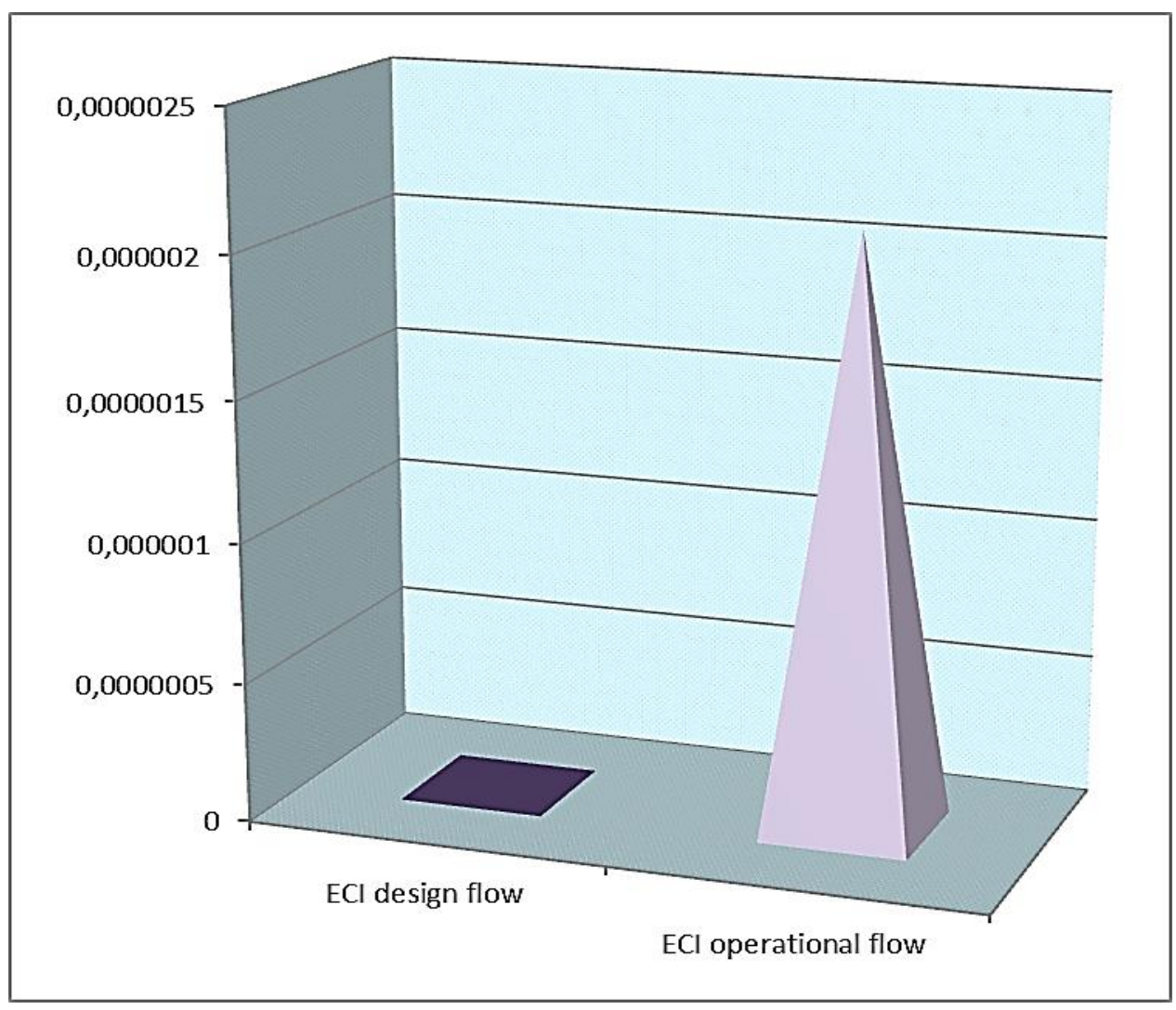

Figure 2. Comparison of energy cost indicators 
$\mathrm{Z}$ is the most important variable in the equation. If the plant is operated under the design flow, $\mathrm{Z}$ is " 0 " (zero). In this study, $\mathrm{Z}$ was calculated as 0.667 . So if the plants are operated under the design flow, energy cost indicator would be lower.

\section{Discussion}

There are many study related to this topic. The use of cost functions is widespread in the literature. Most of the developed models for the wastewater treatment process have been applied to estimate the operational and maintenance cost of the process. Hernandez-Sancho et al. (2011b) [11] applies a cost modelling methodology using statistical information from a sample of 341 wastewater treatment plants in Spain. Castellet-Viciano et al. (2018) [2] investigated the effect of design flow on energy costs for small, middle and large scale of WWTPs. They reported that Z was $0.20,0.40,0.60$ and 0.80 for small-scale plants. Similarly, $Z$ value was 0.667 , in this study. Molinos-Senante et al. (2013) [12] used a cost function model to estimate the cost of the sludge and waste management. Exponential functions have also been preferred to represent the energy intensity of the WWTPs rather than linear equations. Moreover, cost functions for extended aeration and activated sludge also include the volume of wastewater treated and the biological oxygen demand removal efficiency in \%. There was another study related to Molinos-Senante et al. (2018) [13]. In their study, the degree energy intensity (EI) influenced WWTPs was tested using a set of technical variables by modelling the EI of a 305 WWTPs sample grouped into five secondary treatment technologies. Results showed the following two major findings that were WWTPs using conventional activated sludge, extended aeration, trickling biofilters, and biodisks exhibited significant economies of scale in energy use and pollutant removal efficiency demonstrated low impacts on WWTP EI. Plumlee et al. (2014) [14] analysed the cost of the advanced treatment, and in near future Yumin et al. (2016) [15] estimated the operational cost of WWTPs in rural areas. Silva and Rosa (2015) [16] and Verrecht et al. (2010) [17] reported an over cost for a plant designed for twice or three times the mean flow.

\section{Conclusions}

This study demonstrates that the design wastewater flow is not only relevant for the investment cost estimation, but it is also related with the operational costs of the energy consumption. Energy cost indicator and the performance index can be used as an approach method to assess the energy costs of a WWTP.

$\mathrm{Z}$ is the most important variable in the equation. If the plant is operated under the design flow, $\mathrm{Z}$ is " 0 " (zero). So the cost indicator would be lower, if $\mathrm{Z}$ is " 0 ".

The results revealed that energy cost indicator of operational flow was higher than design flow. Their values were $2.1 \times 10^{-8}$ and $2.36 \times 10^{-27}$, respectively.

\section{References}


[1] Metcalf and Eddy. Wastewater Engineering: Treatment and Resource Recovery, 5th ed., McGraw-Hill International Editions, Newyork, USA; 2014.

[2] Castellet-Viciano L, Torregrossa D, Hernández-Sancho F. The relevance of the design characteristics to the optimal operation of wastewater treatment plants: Energy cost assessment J Env Mng 2018;222:275-283.

[3] Racoviceanu AI, Karney BW, Kennedy CA, Colombo AF. Life-cycle energy use and greenhouse gas emissions inventory for water treatment systems. J Infrastruct Syst 2007;13: 261-270.

[4] Yapıcıoğlu P. Greenhouse Gases Emissions Minimization of Wastewater Treatment, MSc thesis, Harran University Graduate School of Natural and Applied Sciences Department of Environmental Engineering, 2018; 96pp.

[5] Parravicini V, Svardal K and Krampe J. Greenhouse gas emissions from wastewater treatment plants. Energy Procedia 2016; 97: 246-253.

[6] Rodriguez-Garcia G, Hospido A, Bagley DM, Moreira MT and Feijoo GA Methodology to estimate greenhouse gases emissions in life cycle inventories of wastewater treatment plants. Environmental Impact Assessment Review 2012; 37:37-46.

[7] Tchobanoglous G, Burton FL, Metcalf \& Eddy. Wastewater Engineering: Treatment, Disposal, and Reuse, third ed. McGraw-Hill Education, New York, 1991.

[8] Campos H, Von Sperling M. Estimation of domestic wastewater characteristics in a developing country based on socio-economic variables. Water Sci. Technol. 1996; 34: 71-77.

[9] Hernandez-Sancho F, Molinos-Senante M, Sala-Garrido R. Cost modelling for wastewater treatment processes. Desalination 2011; 268, 1-5.

[10] Standard Methods for the Examination of Water and Wastewater, 20th ed., American Public Health Association/American Water Works Association/Water Environment Federation, Washington DC, USA, 1998

[11] Hernández-Sancho F, Molinos-Senante M, Sala-Garrido R. Energy efficiency in Spanish wastewater treatment plants: a non-radial DEA approach. Sci. Total Environ. 2011;409: 2693-2699.

[12] Molinos-Senante M, Hernandez-Sancho F, Sala-Garrido R. Cost modeling for sludge and waste management from wastewater treatment plants: an empirical approach for Spain. Desalin Water Treat. 2013; 51: 5414-5420.

[13] Molinos-Senante M, Sala-Garrido R, Iftimi A. Energy intensity modeling for wastewater treatment technologies. Sci. Total Environ. 2018; 630: 1565-1572.

[14] Plumlee MH, Stanford BD, Debroux J, Hopkins DC, Snyder SA. Costs of advanced treatment in water reclamation. Ozone Sci. Eng. 2014; 36: 485-495.

[15] Yumin W, Lei W, Yanhong F. Cost function for treating wastewater in rural regions. Desalin Water Treat. 2016; 57: 17241-17246.

[16] Silva C, Rosa MJ. Energy performance indicators of wastewater treatment: a field study with 17 Portuguese plants. Water Sci. Technol. 2015; 72:510-519.

[17] Verrecht B, Maere T, Nopens I, Brepols C, Judd S. The cost of a large-scale hollow fibre MBR. Water Res. 2010; 44 (18): 5274-5283. 